\title{
Chlorophyll $a$ Fluorescence Parameters in the Evaluation of Oat DH Lines Yield Components
}

\author{
A. NogA ${ }^{1}$, M. WarchoŁ ${ }^{1}$, I. CzyczyŁo-Mysza ${ }^{1}$, I. Marcińska ${ }^{1}$, K. Dziurka ${ }^{1}$, \\ T. WARZECHA ${ }^{2}$ and E. SKRZYPEK ${ }^{1 *}$ \\ ${ }^{1}$ Department of Biotechnology, The Franciszek Górski Institute of Plant Physiology, \\ Polish Academy of Sciences, Niezapominajek 21, 30-239 Kraków, Poland \\ ${ }^{2}$ Department of Plant Breeding and Seed Science, University of Agriculture in Krakow, \\ Łobzowska 24, 31-140 Kraków, Poland
}

Received 5 October 2016; Accepted 14 February 2017;

Communicated by T. Harangozó)

\begin{abstract}
Chlorophyll $a$ fluorescence can provide insight into the ability of plants to tolerate environmental conditions that can damage photosynthetic apparatus and decrease yield. The aim of the study was to determine the relationship between chlorophyll $a$ fluorescence parameters and yield components of oat DH lines. All DH lines significantly differed in chlorophyll $a$ fluorescence parameters and yield components. The overall performance index of PSII photochemistry (PI), showed the highest variation between DH lines, whereas the lowest had the ratio of variable to maximum fluorescence $\left(\mathrm{F}_{\mathrm{v}} / \mathrm{F}_{\mathrm{m}}\right)$. The highest differences were observed in the number of grains per plant (21.3 to 600). Thousand-grain weight varied from $17.82 \mathrm{~g}$ to $41.01 \mathrm{~g}$ and the biomass from $8.01 \mathrm{~g}$ to $29.31 \mathrm{~g}$. The highest negative correlations were found between $\mathrm{F}_{\mathrm{v}} / \mathrm{F}_{\mathrm{m}}$, Area (pool size of electron acceptors from PSII), PI and grain number per plant and biomass. Positive correlations were observed between light energy absorption (ABS/CS), grain number per plant and biomass, as well as the amount of excitation energy trapped in PSII reaction centers $\left(\mathrm{TR}_{\mathrm{o}} / \mathrm{CS}\right)$ and biomass. Principal component analysis of chlorophyll $a$ fluorescence parameters, together with yield components, discriminated two oat DH lines groups according to their photosynthetic efficiency and yield.
\end{abstract}

Keywords: Avena sativa L., DH lines, chlorophyll a fluorescence, yield, principal component analysis

\section{Introduction}

Oat (Avena sativa L.) is a very important cereal crop belonging to Poaceae family that can be used not only as a valuable feed for animals, but also as an important food ingredient in human diet. We can distinguish two main groups among cultivated hexaploid oat varieties: husk oat and varieties called naked oat. Although naked oat varieties produce lower yields than the conventional husked types, the naked oat has considerable nutritional benefits, as they produce more nutrient contents (Biel et al. 2009, 2014). Oat exerts a beneficial effect on human health due to its protein, carbohydrate, fiber, vitamin and min-

*Corresponding author; E-mail: e.skrzypek@ifr-pan.edu.pl; Phone: 4812 4251833; Fax: 484251844 
eral contents (Peterson 2004). Oat can be used not only as a food for animals and humans, but also as a raw material for the production of medicinal and cosmetic products (Peterson et al. 2005). Wide range of applications of oat results in a high demand for new varieties.

Currently, a series of biotechniques are applied on plant breeding in order to shorten the breeding period of new varieties, and one of them is haploidization. It takes 6-10 years to inbred a new variety for traditional method. Doubled haploids are characterized by a high level of homozygosity. This allows to reduce the selection time of new varieties even to a single vegetative season (Marcińska et al. 2013). In addition, doubled haploids can be useful as components in genetic map construction. Production of DH mapping populations with markers linked to the developing trait is an important application of the technology. DHs represent homozygous, immortal and true-breeding lines that can be repeatedly phenotyped. They are therefore ideal for studying complex traits with quantitative inheritance, which may require replicated trials in several years and localization for accurate phenotyping and marker development (Tuvesson et al. 2007).

The main purpose of conventional and non-conventional plant breeding programs is the improvement of plant productivity. This involves increasing the total biomass of aerial plant parts. Thus, increasing the biomass is the main target for breeders. Photosynthetic efficiency is a major physiological determinant of net carbon gain. Plant productivity can be evaluated by studying the activity of photosynthetic apparatus components, such as chlorophyll fluorescence parameters (Czyczyło-Mysza et al. 2013). Changes in the photosynthetic apparatus have been frequently reported and widely discussed by many chlorophyll fluorescence studies, also as an indirect indicator of plant productivity. Chlorophyll $a$ fluorescence is known as a convenient, non-invasive, highly sensitive, and rapid technique that allows to estimate photosynthetic performance in plants (Oxborough and Baker 1997; Baker and Rosenqvist 2004; Żurek et al. 2014). This method is used for rapid screenings of large number of plants (Baker and Rosenqvist 2004). Chlorophyll $a$ fluorescence parameters allow to detect even subtle differences in the activity of photosynthetic apparatus in plants (Czyczyło-Mysza et al. 2013). The basic principle of chlorophyll $a$ fluorescence parameter measurements is that the light energy absorbed by chlorophyll molecules in a leaf can be converted in three ways. The first one is to drive photosynthesis (photochemistry), while the excess energy can be dissipated as heat or it can be re-emitted as light chlorophyll fluorescence. These three processes occur in competition, such that any increase in the efficiency of one will result in a decrease in the yield of the other two. This means that by measuring the yield of chlorophyll fluorescence, information about changes in the efficiency of photochemistry and heat dissipation can also be gained (Maxwell and Johnson 2000). Chlorophyll $a$ fluorescence parameters allow to estimate the photochemical efficiency of photosystem II, the efficiency of excitation energy utilization in the photosynthesis process, the level of openness of reaction centers as well as the amount of energy reaching the photosynthetic apparatus dissipated as heat (Baker and Rosenqvist 2004; Hura et al. 2014). Measurement of chlorophyll $a$ fluorescence provides information about changes in the efficiency of photochemistry and heat scattering (Żurek et al. 2014). Some of chlorophyll fluorescence parameters can be help- 
ful in estimating the leaf photosynthetic $\mathrm{CO}_{2}$ assimilation rate and leaf photosynthetic performance (Hura et al. 2014). The relation between chlorophyll $a$ fluorescence parameters and leaf photosynthetic performance can be used in screening programs that seek to identify improved plant performance. Chlorophyll $a$ fluorescence is a very sensitive probe of the physiological status of leaves (Baker and Rosenqvist 2004). This method is widely used in assessing plant responses to environmental stress, such as water stress, heat stress, salt stress or chilling stress (Sayed 2003).

The aim of this research was to looking for the differentiation between photosynthetic efficiency and yield components in oat DH lines. Most attention was paid to determining the possible correlations between chlorophyll $a$ fluorescence parameters and selected yield components of oat DH lines.

\section{Materials and Methods}

\section{Plant material}

The experiments were performed on all oat DH lines (Table S1*) obtained in the Institute of Plant Physiology of the Polish Academy of Sciences by wide crossing method by pollination with maize, as described by Marcińska et al. (2013). Oat plants ( $F_{1}$ progeny) for DH line production were derived from Strzelce Plant Breeding Ltd., Małopolska Plant Breeding Ltd. HBP Polanowice and Danko Plant Breeding Ltd.

One hundred and thirty-seven oat DH lines were studied using spring sowings (23 April 2014) single spacing into the mixture of soil with sand $(3: 1 \mathrm{v} / \mathrm{v})$ in $3 \mathrm{~L}$ volume pots in five replicates (685 plants). Pots were watered regularly to ensure that soil water content was kept on the level of $70 \%$ field water capacity (FWC). FWC is the maximum amount of water that can be retained by the soil by the gravity filtration. During the experiment plants were fertilized with a liquid Hoagland medium once a week (Hoagland and Arnon 1938). Plants were placed in an open-sided greenhouse and grown until harvest in August. Experiment was conducted at the Institute of Plant Physiology of the Polish Academy of Sciences, Krakow, Poland. For oat DH lines, chlorophyll $a$ fluorescence parameters and yield components were measured.

\section{Chlorophyll a fluorescence induction}

Chlorophyll fluorescence measurements were carried out using a portable fluorometer (Handy Plant Efficiency Analyzer, Handy PEA; Hansatech Instruments Ltd., King's Lynn, Norfolk, UK) at ambient temperature after at least 15 min of leaf adaptation to dark conditions in leaf-clips. All measurements were taken using a saturating pulse of 3,000 $\mu \mathrm{mol} \mathrm{m} \mathrm{m}^{-2} \mathrm{~s}^{-1}$, pulse duration of $1 \mathrm{~s}$, and fixed gain $(0.8 \times)$. The following parameters were calculated per excited leaf cross-section $(\mathrm{CS}): \mathrm{F}_{\mathrm{v}} / \mathrm{F}_{\mathrm{m}}$ (maximum photochemical efficiency of PS II), PI (overall performance index of PSII photochemistry), ABS/CS (light energy absorption), $\mathrm{TR}_{\mathrm{o}} / \mathrm{CS}$ (excitation energy trapped in PSII reaction centers) and $\mathrm{ET}_{\mathrm{o}} / \mathrm{CS}$ (en-

\footnotetext{
*Further details about the Electronic Supplementary Material (ESM) can be found at the end of the article.
} 
ergy used for electron transport). The measurements were performed on plants in the end of heading (when inflorescence completely emerged), on the fully expanded flag leaf in three replicates for each plant of oat DH lines.

\section{Chosen yield components}

The oat DH line yield components: thousand-grain weight (TGW), the number of grains per plant and biomass weight per plant were evaluated in the stage of full maturity.

\section{Statistical analysis}

The analysis of variance, Pearson's linear correlation coefficient and principal component analysis (PCA) were carried out using the STATISTICA 10.0 (Stat-Soft, Inc., Tulsa, OK, USA) software.

\section{Results}

\section{Statistical analysis}

The analysis of variance showed that the oat DH lines varied in values of chlorophyll $a$ fluorescence parameters and yield components (Table 1). All traits showed high significance at a probability level of 0.001 .

\section{Chlorophyll a fluorescence parameters}

Changes in the photosynthetic apparatus were observed in relation to the origin of particular oat line. Among the measured parameters, $\mathrm{F}_{\mathrm{v}} / \mathrm{F}_{\mathrm{m}}$ (maximum photochemical efficiency) demonstrated the lowest variation between the DH lines. The $\mathrm{F}_{\mathrm{v}} / \mathrm{F}_{\mathrm{m}}$ parameter varied from 0.711 to 0.835 and Area from 18099 to 64033 (Table 1, Fig. S1A, B). Changes in PI (overall performance index of PSII photochemistry based on the equal absorption) corresponded closely to $\mathrm{ABS} / \mathrm{CS}$ (light energy absorption), $\mathrm{TR}_{\mathrm{o}} / \mathrm{CS}$ (excitation energy trapped in PSII reaction centers) and $\mathrm{ET}_{\mathrm{o}} / \mathrm{CS}$ (energy used for electron transport). The PI, ABS/CS, TR $/$ $\mathrm{CS}$ and $\mathrm{ET}_{\mathrm{o}} / \mathrm{CS}$ parameters divided the investigated oat DH lines into two groups. PI was significantly lower in lines 92-110 compared to other lines, whereas $\mathrm{ABS} / \mathrm{CS}, \mathrm{TR}_{\mathrm{o}} / \mathrm{CS}$ and $\mathrm{ET}_{\mathrm{o}} / \mathrm{CS}$ had the highest values in these lines (Fig. S1C-F). The values of PI ranged between 0.443 and $6.417, \mathrm{ABS} / \mathrm{CS}$ from 272.20 to 615.33 , $\mathrm{TR}_{\mathrm{o}} / \mathrm{CS}$ from 221.51 to 461.45 , and $\mathrm{ET}_{\mathrm{o}} / \mathrm{CS}$ from 135.92 to 222.17 (Table 1). The PI parameter showed the highest variation among other chlorophyll fluorescence parameters, as indicated by variation coefficient equal to $34.6 \%$, whereas the lowest variation was recorded for $\mathrm{F}_{\mathrm{v}} / \mathrm{F}_{\mathrm{m}}(3.4 \%)$.

\section{Chosen yield components}

All the presented traits for yield components strongly depend on the examined oat DH line. The highest differences were observed for grain number per plant (21.3 to 600); 
Table 1. The mean values, minimum (Min), maximum (Max) and coefficient of variance (CV) (\%) of chlorophyll $a$ fluorescence parameters $\left(\mathrm{F}_{\mathrm{v}} / \mathrm{F}_{\mathrm{m}}\right.$, Area, PI, ABS/CS, TR $\left./ \mathrm{CS}, \mathrm{ET}_{\mathrm{o}} / \mathrm{CS}\right)$, thousand-grain weight $[\mathrm{g}]$ (TGW), grain number per plant and biomass [g] of oat DH lines. On the right side F-statistics from analysis of variance for the measured parameters

\begin{tabular}{|l|c|c|c|c|c|}
\hline \multicolumn{1}{|c|}{ Trait } & Mean & Min & Max & CV (\%) & F-statistics \\
\hline $\mathrm{F}_{\mathrm{v}} / \mathrm{F}_{\mathrm{m}}$ & 0.791 & 0.711 & 0.835 & 3.35 & $4.15^{* * *}$ \\
\hline Area & 33230 & 18099 & 64033 & 19.75 & $9.71 * * *$ \\
\hline $\mathrm{PI}$ & 3.192 & 0.443 & 6.417 & 34.55 & $9.67 * * *$ \\
\hline $\mathrm{ABS} / \mathrm{CS}$ & 358.15 & 272.20 & 615.33 & 8.46 & $20.49^{* * *}$ \\
\hline TR $/ \mathrm{CS}$ & 282.79 & 221.51 & 461.45 & 7.05 & $34.47 * *$ \\
\hline ET $/ \mathrm{CS}$ & 169.07 & 135.92 & 222.17 & 8.42 & $8.29 * * *$ \\
\hline TGW [g] & 29.48 & 17.82 & 41.01 & 15.29 & $3166.26 * * *$ \\
\hline Grains number/plant & 321.63 & 21.3 & 600.00 & 40.56 & $3.41 * * *$ \\
\hline Biomass [g] & 19.35 & 8.01 & 29.31 & 28.21 & $3.29 * * *$ \\
\hline
\end{tabular}

$* * *$ Significant at $\mathrm{p} \leq 0.001$.

variation coefficients were $40.56 \%$ (Table 1). The lines numbered 19, 21, 44, 86, 100, 118, 123 and 129 formed the lowest number of seeds, while the lines 3, 26, 27 and 77 the highest (Table S1). The variation in thousand-grain weight was not as high as in the grain number per plant (15.3\% and 40.56\% CV, respectively) (Table 1). Thousand-grain weight varied from $17.82 \mathrm{~g}$ (DH line 100) to $41.01 \mathrm{~g}$ (DH line 92). Biomass ranged from $8.01 \mathrm{~g}$ (DH line 82) to $29.31 \mathrm{~g}$ (DH line 3) (Table S1).

\section{Correlation between chlorophyll a fluorescence parameters and yield components}

Furthermore, significant correlations were also found between chlorophyll $a$ fluorescence parameters and yield components (Table S2). Negative correlations were observed between $\mathrm{F}_{\mathrm{v}} / \mathrm{F}_{\mathrm{m}}$, Area, PI, grain number and biomass. Positive correlations were observed between $\mathrm{ABS} / \mathrm{CS}$ and grain number per plant and biomass; and also between $\mathrm{TR}_{\mathrm{o}} / \mathrm{CS}$ and biomass. Thousand-grain weight showed no correlations with any of chlorophyll $a$ fluorescence parameters. Correlations between chlorophyll $a$ fluorescence parameters were statistically significant at the 0.001 probability level. $\mathrm{F}_{\mathrm{v}} / \mathrm{F}_{\mathrm{m}}$ and Area correlated positively with PI, but negatively with $\mathrm{ABS} / \mathrm{CS}$ and $\mathrm{TR}_{\mathrm{o}} / \mathrm{CS}$. There was a positive correlation between $\mathrm{F}_{\mathrm{v}} / \mathrm{F}_{\mathrm{m}}$ and Area, while both parameters showed no correlation with $\mathrm{ET}_{\mathrm{o}} / \mathrm{CS}$. The PI parameter was negatively correlated with $\mathrm{ABS} / \mathrm{CS}, \mathrm{TR}_{\mathrm{o}} / \mathrm{CS}$ and $\mathrm{ET}_{\mathrm{o}} / \mathrm{CS}$. Moreover, positive correlations between $\mathrm{ABS} / \mathrm{CS}, \mathrm{TR}_{\mathrm{o}} / \mathrm{CS}$ and $\mathrm{ET}_{\mathrm{o}} / \mathrm{CS}$ were also found. Among the presented yield traits, positive correlation were observed for thousand-grain weight and grain number as well as grain number with biomass. 


\section{Principal component and biplot analysis}

Biplot analysis is a better approach to identify superior oat DH lines in terms of yield relative to chlorophyll $a$ fluorescence parameters, as the lines are simultaneously compared for all the traits. Biplot analysis confirmed correlation for all the studied traits (Fig. 1A). Acute angle between the measured parameters means that positive correlation was observed, obtuse angle - negative, and right angle - no correlation. The first two principal components (PCA) accounted for about $73.33 \%$ of the total variation of the data set. PCA revealed that the first PC explained $48.18 \%$ of the variation with $\mathrm{F}_{\mathrm{v}} / \mathrm{F}_{\mathrm{m}}, \mathrm{PI}$, Area, $\mathrm{ABS} / \mathrm{CS}, \mathrm{TR}_{\mathrm{o}} / \mathrm{CS}, \mathrm{ET}_{\mathrm{o}} / \mathrm{CS}$, thousand-grain weight (TGW), number of grains per plant and biomass. The second PC explained $25.15 \%$ of the total variability. PCA indicated that chlorophyll $a$ fluorescence parameters with yield components could discriminate between the oat DH lines (Fig. 1B). This analysis separated the lines according to their photosynthetic activity and yield. Thus, the lines with lower PC1 and PC2 were superior in terms of photosynthetic parameters. These lines demonstrated high chlorophyll $a$ fluorescence parameters. The remaining lines were grouped tightly nearly in the middle of PC1 and PC2 intersection. Such division of oat lines was mainly due to the parameters associated with energy absorption and trapping ( $\mathrm{ABS} / \mathrm{CS}, \mathrm{TR}_{\mathrm{o}} / \mathrm{CS}, \mathrm{ET}_{\mathrm{o}} / \mathrm{CS}$ ) (data not shown). PCA revealed that the first $\mathrm{PC}$ explained $88.82 \%$ of the variation with $\mathrm{ABS} / \mathrm{CS}, \mathrm{TR}_{\mathrm{o}} / \mathrm{CS}$ and $\mathrm{ET}_{\mathrm{o}} / \mathrm{CS}$. The second PC explained $10.98 \%$ of the total variability. These parameters are able to separate and identify lines with high photosynthetic activity.
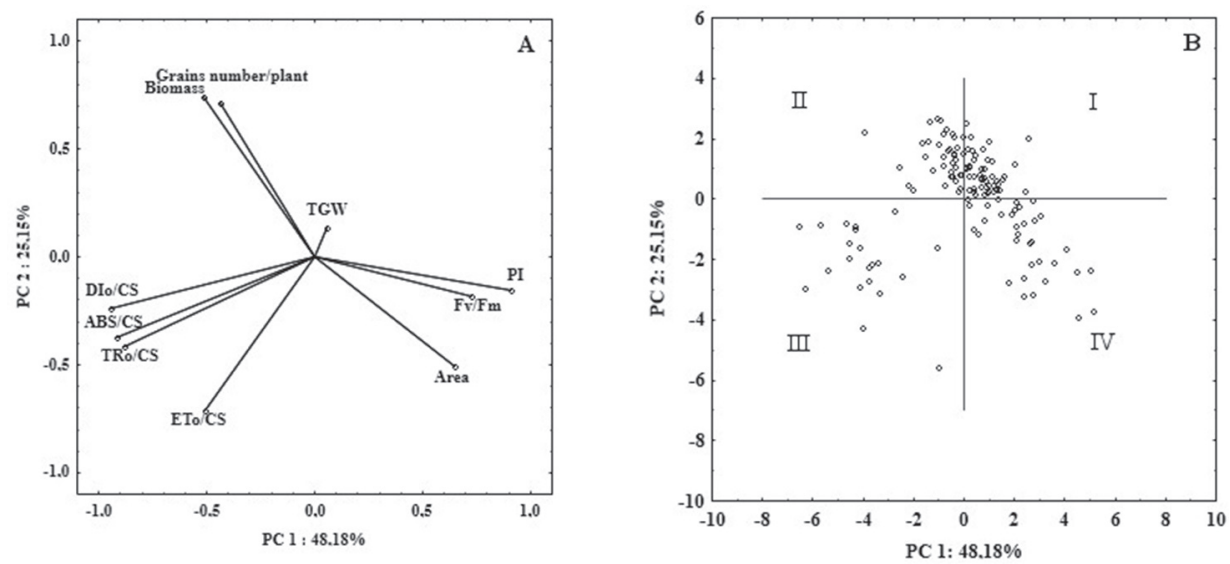

Figure 1. Biplot based on first two principal component axes (PC 1 and PC 2) for chlorophyll $a$ fluorescence parameters $\left(\mathrm{PI}, \mathrm{F}_{\mathrm{v}} / \mathrm{F}_{\mathrm{m}}\right.$, Area, $\mathrm{DI}_{\mathrm{o}} / \mathrm{CS}, \mathrm{ABS} / \mathrm{CS}, \mathrm{TR}_{\mathrm{o}} / \mathrm{CS}, \mathrm{ET}_{\mathrm{o}} / \mathrm{CS}$ ) and yield components (biomass, grain number/ plant, thousand-grain weight (TGW)) of 137 oat DH lines (A) and distribution of 137 oat DH lines based on the first two components obtained from principal component analysis (B), I quadrant - oat DH lines numbered: $1,2,4,9,12,15,20,23,24,30,31,42,48,50,51,52,54,56,57,58,59,61,62,64,65,67,71,73,76,77,78$, $81,83,84,87,112,117,121,124,127,128,130,132,133,134,136,137$, II quadrant - 3, 5, 6, 7, 11, 16, 17, $18,22,25,26,27,29,32,33,34,35,36,39,46,49,53,55,63,66,70,75,79,111,113,114,115,119,120$, 122, 126, 131, III quadrant - 14, 37, 92, 93, 94, 95, 96, 97, 98, 99, 100, 101, 102, 103, 104, 105, 106, 107, 108, 109,110 , IV quadrant $-8,10,13,19,21,28,38,40,41,43,44,45,47,60,68,69,72,74,80,82,85,86,88$, $89,90,91,116,118,123,125,129,135$. Details of oat DH lines chlorophyll $a$ fluorescence parameters and yield components are given in Figure $\mathrm{S} 1$ and in Table S1 


\section{Discussion}

The chlorophyll $a$ fluorescence method provides useful information on the quantitative and qualitative changes in photosynthesis. Among the available experimental techniques for investigating photosynthetic activity in plants, chlorophyll $a$ fluorescence can be an excellent tool, providing information on the relationship between the structure (molecular composition and conformation) and function of PSII (Falqueto et al. 2010). This method was used to assess PSII photochemistry during leaf senescence in cultivars with different grain yield potentials. It was shown that the photosynthetic activity was dependent on the cultivar. Rice cultivar BRS Firmeza showed higher activity of the photosynthetic apparatus in comparison to the cultivar BRS Pelota during the grain filling stage (Falqueto et al. 2009). Earlier loss of effective photochemical efficiency should be a good indicator of senescence in 'BRS Pelota' plants, indicating that the rice cultivar with higher grain yield potential senesces before the one with lower grain yield.

According to Plachton et al. (1989), measurements of chlorophyll $a$ fluorescence can also be used as a tool to determine the overall performance of the photosynthetic apparatus and may provide a solution allowing to analyze the performance of different genotypes within a species. Chlorophyll $a$ fluorescence also enabled the detection of differences in the photosynthetic apparatus of oat DH lines. Our results allowed to divide oat $\mathrm{DH}$ lines into two groups differing in chlorophyll $a$ fluorescence parameters. The most differentiating parameter was the overall performance index of PSII photochemistry, which includes the information about the density of fully active reaction centers, efficiency of electron movement by trapped exciton into the electron transport chain beyond the $\mathrm{Q}_{\mathrm{A}}$ and the probability that an absorbed photon will be trapped by reaction centers. PI reflects the functionality of both photosystems I and II and gives quantitative information on the current state of plant performance (Strasser et al. 2004).

The measurement of chlorophyll $a$ fluorescence is frequently used by breeders as a biomarker, bioindicator or selection criterion. It provides reliable information about plant photosynthetic efficiency that can be correlated to the yield of crops (Kalaji and Guo 2008). Chlorophyll fluorescence parameters have been used to detect even subtle differences in the activity of photosynthetic apparatus between genotypes of crop plants (Maxwell and Johnson 2000; Czyczyło-Mysza et al. 2013). Characteristics of chlorophyll fluorescence are indicative of various aspects of plant photosynthetic efficiency, which determine plant productivity, and for crop plants, ultimately the yield (Czyczyło-Mysza et al. 2013).

According to Plachton et al. (1989), chlorophyll fluorescence transient can be used as a genetic marker of productivity in barley. They discovered that the biological yield was correlated with the leaf area, whereas the economic yield was more dependent on the green area duration of the leaf or the combination of the two factors, leaf area and green area duration. Chlorophyll fluorescence parameters were negatively correlated with the net photosynthesis and positively with the leaf area. The yield was not correlated with the maximum photosynthetic activity at the flowering stage, but it was correlated with the chlorophyll fluorescence parameters. The experiment performed by Slapakauskas and 
Ruzgas (2005) demonstrated that PSII fluorescence parameters correlated with plant characteristics and crop productivity. Hura et al. (2009) found significant correlations between the yield of triticale and certain parameters of chlorophyll fluorescence and leaf gas exchange. In our experiment, chlorophyll $a$ fluorescence parameters $\left(\mathrm{F}_{\mathrm{v}} / \mathrm{F}_{\mathrm{m}}\right.$, Area, PI) were negatively correlated with grain number per plant and biomass, whereas ABS/CS parameter was positively correlated with grain number per plant and biomass. Such significant correlations between chlorophyll $a$ fluorescence parameters and yield components confirm their suitability as productivity markers in oat DH lines. Furthermore, principal component analysis, based on the chlorophyll fluorescence parameters and yield components, indicate that there is a close correspondence between them in the examined lines.

Nevertheless, according to Slapakauskas and Ruzgas (2005), it is important to know the physiological background of the newly developed varieties and the correlation between physiological and agronomic characteristics of the plant. In order to select plant breeding material using the chlorophyll fluorescence method, it is necessary to group varieties or breeding lines according to the dates of maturity. In our study, the difference between the earliest and the latest maturity of DH lines was twenty-four days, but there were no significant differences in chlorophyll $a$ fluorescence during that period of time.

Efforts have been devoted to identify differences in chlorophyll fluorescence among rice varieties with various yield potentials. The results of this study showed that rice varieties differing in grain yield were characterized by significant differences in the capacity of absorption and use of light (Jiang et al. 2002). It was previously showed that the leaf photosynthetic capacity was the most important factor in obtaining higher grain yield of maize (Shao et al. 2013). We have observed in our experiment that the lower the values of the maximum photochemical efficiency and the pool size of electron acceptors from PSII (proportional to the oxidized plastoquinone pool and overall performance index), the higher the number of seeds and plant biomass. We have also found that higher values of the parameters connected with light energy absorption and excitation energy trapped in PSII reaction centers correlated with higher biomass generation by the oat plants. In addition, higher amounts of light energy absorbed enabled setting greater number of seeds by the oat DH lines.

Chlorophyll $a$ fluorescence measurements can be used to investigate the 'vitality' of plants in vivo and how they respond to different environmental conditions. This method was applied to screen barley (Hordeum vulgare L.) genotypes for salinity tolerance (Belkhodja et al. 1994). The $\mathrm{F}_{\mathrm{v}} / \mathrm{F}_{\mathrm{m}}$ ratio was used to evaluate cold acclimation and freezing tolerance of winter and spring oats (Avena sativa L.) and compare them to the efficiency of excitation capture by PSII RC; moreover, it was used as a rapid method for screening oat cultivars for chilling tolerance (Herzog and Olszewski 1998).

In conclusion, the findings of this study showed that there is a relationship between chlorophyll $a$ fluorescence parameters and yield components of oat. Highly significant correlations were found between the following fluorescence parameters: $F_{v} / F_{m}$ (maximum photochemical efficiency), Area (pool size of electron acceptors from PSII; proportional to the oxidized plastoquinone pool), PI (overall performance index of PSII photo- 
chemistry) and grain number per plant and biomass. They indicated that the measurement of chlorophyll fluorescence is a promising method in predicting yield. It should also be noted that the principal component analysis identified oat lines with high photosynthetic efficiency.

\section{Acknowledgement}

The research was funded by the F. Górski Institute of Plant Physiology, Polish Academy of Sciences.

\section{References}

Baker, N., Rosenqvist, E. 2004. Application of chlorophyll fluorescence can improve crop production strategies: an examination of future possibilities. J. Exp. Bot. 55:1607-1621.

Belkhodja, R., Morales, F., Abadia, A., Gomez-Aparisi, J., Abadia J. 1994. Chlorophyll fluorescence as a possible tool for salinity tolerance screening in barley (Hordeum vulgare L.). Plant Physiol. 104:667-673.

Biel, W., Bobko, K., Maciorowski, R. 2009. Chemical composition and nutritive value of husked and naked oats grain. J. Cereal Sci. 49:413-418.

Biel, W., Jacyno, E., Kawęcka, M. 2014. Chemical composition of hulled, dehulled and naked oat grains. Afr. J. Anim. Sci. 44:189-197.

Czyczyło-Mysza, I., Tyrka, M., Marcińska, I., Skrzypek, E., Karbarz, M., Dziurka, M., Hura, T., Dziurka, K., Quarrie, S.A. 2013. Quantitative trait loci for leaf chlorophyll fluorescence parameters, chlorophyll and carotenoid contents in relation to biomass and yield in bread wheat and their chromosome deletion bin assignments. Mol. Breed. 32:89-210.

Falqueto, A.R., Cassol, D., Magalhaes Junior, A.M., Oliviera, A.C., Bacarin, M.A. 2009. Physiological analysis of leaf senescence of two rice cultivars with different yield potential. Pesq. Agropec. Bras. 44:695-700.

Falqueto, A.R., Silva, F.S.P., Cassol, D., Magalhaes Junior, A.M., Oliviera, A.C., Marcos, A.B. 2010. Chlorophyll fluorescence in rice: probing of senescence driven changes of PSII activity on rice varieties differing in grain yield capacity. Braz. J. Plant Physiol. 22:35-41.

Herzog., H., Olszewski, A. 1998. A rapid method for measuring freezing resistance in crop plants. J. Agron. Crop Sci. 181:71-79.

Hoagland, D.R., Arnon, D.I. 1938. A water culture method for growing plants without soil. Circ. Univ. Calif, Agric. Exp. Stn. No. 347.

Hura, T., Hura, K., Grzesiak, M.T. 2009. The usefulness of chlorophyll fluorescence parameters in harvest prediction in 10 genotypes of winter triticale under optimal growth conditions. Plant Biosyst. 143:496-503.

Hura K., Hura, T., Grzesiak, M. 2014. Function of the photosynthetic apparatus of oilseed winter rape under elicitation by Phoma lingam phototoxins in relation to carotenoid and phenolic levels. Acta Physiol. Plant. 36:295-305.

Jiang, H., Wang, X.-H., Deng, Q.-Y., Yuan, L.-P., Xu, D.-Q. 2002. Comparison of some photosynthetic characters between two hybrid rice combinations differing in yield potential. Photosynthetica 40:133-137.

Kalaji, H.M., Guo, P. 2008. Chlorophyll Fluorescence: A Useful Tool in Barley Plant Breeding Programs. Photochemistry Research Progress. Nova Science Publishers. New York, USA. pp. 447-471.

Marcińska, I., Nowakowska, A., Skrzypek, E., Czyczyło-Mysza, I. 2013. Production of double haploids in oat (Avena sativa L.) by pollination with maize (Zea mays L.). Centr. Eur. J. Biol. 8:306-313.

Maxwell, K., Johnson, G.N. 2000. Chlorophyll fluorescence - a practical guide. J. Exp. Bot. 51(345):659-668.

Oxborough, K., Baker, N.R. 1997. Resolving chlorophyll $a$ fluorescence images of photosynthetic efficiency into photochemical and non-photochemical components - calculation of $\mathrm{qP}$ and $\mathrm{F}_{\mathrm{v}} / \mathrm{F}_{\mathrm{m}}$ without measuring $\mathrm{F}_{0}$. Photosynthetic Res. 54:135-142. 
Peterson, D.M. 2004. Oat - a multifunctional grain. In: PeltonenSaino, P., Topi-Hulmi, M. (eds), Proc. 7th Int. Oat Conf., Helsinki, Finland. Agrifood Research Reports 51:21-26.

Peterson, D.M., Wasenberg, D.M., Burrup, D.E., Charles, A.E. 2005. Relationship among agronomic traits and grain composition in oat genotypes grown in different environments. Crop Sci. 45:1249-1255.

Plachton, C., Saraffi, A., Ecochard, R. 1989. Chlorophyll fluorescence transient as a genetic marker of productivity in barley. Euphytica 42:269-273.

Sayed, O.H. 2003. Chlorophyll fluorescence as a tool in cereal crop research. Photosynthetica 41:321-330.

Shao, G., Li, Z., Ning, T., Zheng, Y. 2013. Responses of photosynthesis, chlorophyll fluorescence and grain yield of maize to controlled-release urea and irrigation after anthesis. J. Plant Nutr. Soil Sci. 176:595-602.

Slapakauskas, V., Ruzgas, V. 2005. Chlorophyll fluorescence characteristic of different winter wheat varieties. Agronomy Res. 3:203-209.

Strasser, R.J., Tsimilli-Michael, M., Srivastava, A. 2004. Analysis of the fluorescence transient. In: George, C., Papageorgiou, C., Govindjee (eds), Chlorophyll Fluorescence: A Signature of Photosynthesis. Advances in Photosynthesis and Respiration Series. Springer. Dordrecht, The Netherlands. pp. 321-362.

Tuvesson, S., Daytag, C., Hagberg, P., Manninen, O., Tanhuanpää, P., Tenhola-Roinien, T., Kiviharju, E., Weyen, J., Förster, J., Schondelmaier, J., Lafferty, J., Marn, M., Fleck, A. 2007. Molecular markers and doubled haploids in European plant breeding programmes. Euphytica 158:305-312.

Żurek, G., Rybka, K., Pogrzeba, M., Krzyżak, J., Prokopiuk, K. 2014. Chlorophyll $a$ fluorescence in evaluation of the effect of heavy metal soil contamination of parental grasses. PLoS One 9:1-10.

\section{Electronic Supplementary Material (ESM)}

Electronic Supplementary Material (ESM) associated with this article can be found at the website of CRC at http://www.akademiai.com/content/120427/

Electronic Supplementary Table S1. Oat DH line yield components: thousand-grain weight (TGW) [g], grain number per plant and biomass [g]

Electronic Supplementary Table S2. Correlation matrix for chlorophyll $a$ fluorescence parameters $\left(\mathrm{F}_{\mathrm{v}} / \mathrm{F}_{\mathrm{m}}\right.$, Area, $\mathrm{PI}, \mathrm{ABS} / \mathrm{CS}, \mathrm{TR}_{\mathrm{o}} / \mathrm{CS}$, and $\left.\mathrm{ET}_{\mathrm{o}} / \mathrm{CS}\right)$ and yield components: thousand-grain weight $[\mathrm{g}](\mathrm{TGW})$, grain number per plant and biomass $[\mathrm{g}]$ of oat DH lines

Figure S1. The chlorophyll $a$ fluorescence parameters: A $-\mathrm{F}_{\mathrm{v}} / \mathrm{F}_{\mathrm{m}}, \mathrm{B}-\mathrm{Area}, \mathrm{C}-\mathrm{PI}, \mathrm{D}-\mathrm{ABS} / \mathrm{CS}, \mathrm{E}-\mathrm{TR} / \mathrm{CS}$ and $\mathrm{F}-\mathrm{ET}_{\mathrm{o}} / \mathrm{CS}$ of 137 oat DH lines. LSD - the lowest significant difference at $\mathrm{p} \leq 0.05$ 